\title{
Evaluation of Blood Magnesium Level and Functional State of Women at the Threat of Permanent Pregnancy
}

\author{
E.A. Dubrovina ${ }^{1}$, G.V. Dubrovina ${ }^{2}$ and S.V. Notova ${ }^{3}$
}

\author{
${ }^{1}$ Orenburg State Medical University \\ ${ }^{2}$ Orenburg Clinical Perinatal Center \\ ${ }^{3}$ Orenburg State University, Orenburg, Russia \\ ${ }^{*}$ Corresponding author. Email: biochimiya@mail.osu.ru
}

\begin{abstract}
During pregnancy, a woman is more susceptible to magnesium deficiency, due to an increase in the need for this trace element. Magnesium is essential for the normal course of the processes of mitosis and meiosis, which is the key to the formation of a genetically healthy embryo. Disruption of the processes of mitosis and meiosis in early pregnancy can lead to the formation of sporadic genetic anomalies of the embryo and miscarriage. The article presents the results of a study that assessed the level of magnesium in the blood and the functional state in pregnant women with a threat of miscarriage. The results obtained confirmed the effectiveness of the combined use of micronized progesterone and a magnesium preparation, since this helped to reduce certain side effects of progesterone, and improved the adaptation of the cardiovascular system.
\end{abstract}

Keywords: magnesium, interruption of pregnancy, micronized progesterone, adaptive potential of the cardiovascular system, functional state

\section{INTRODUCTION}

The elemental composition of the human body consists of $99 \%$ of 12 basic chemical elements, among which magnesium ranks fourth after potassium, calcium and sodium. Being an essential macronutrient for cells and tissues, magnesium participates in many physiological processes that ensure the normal functioning of the body: in the synthesis of enzymes (ATP substrate, creatine kinase, hexokinase, etc.), direct activation of enzymes, regulation of cell membrane function (stabilization of cell membranes, cell adhesion, transmembrane flow of electrolytes), antagonism with calcium (muscle contraction / relaxation, release of neurotransmitters, excitability of specialized conduction system of the heart), in plastic processes (protein synthesis and catabolism, exchange of nucleic acids and lipids, mitochondria) [1]

Of all the periods of a person's life, the intrauterine period is the most responsible and largely determines the future fate of the child. It is characterized by rapid and rapid growth and development of the body: during pregnancy, 2 billion cells are formed from one cell, from which fetal tissues and organs are built. The more intensive the development, the more active the metabolism in cells and tissues, the heavier and more destructive the harmful effects on them. Two-thirds of diseases and disorders in a child after birth and an adult in later life have their roots in this period of development. The fetus is most vulnerable in the first 3 months, when complex processes of the formation of the nervous system and the laying of internal organs occur. Science and practice have proven that a healthy child is born only from healthy parents during the normal course of pregnancy and childbirth, and world statistics show that currently only one child out of ten is born absolutely healthy [2].

The fetus in the mother's womb is subject to two guiding forces: hereditary information and the specific conditions in which it develops. To date, certain data 
have been accumulated regarding the effect of magnesium on the fetus. It is known that the trophoblast is involved in the active transport of magnesium ions and this leads to an increased magnesium content in the fetal blood compared to the mother's blood. In clinical observations and experiments, it has been established that magnesium deficiency during pregnancy can cause a delay in fetal development, brain damage and deterioration of newborn survival [3].

Numerous studies conducted over the past decades have shown that normal levels of magnesium in body tissues are a fundamental parameter that directly affects the health of a child. The normal level of magnesium in the body is recognized as a fundamental constant that controls human health. The physiological balance of magnesium is a prerequisite for the implementation of an optimal program for the development of the child's nervous system at all stages of development, starting from the prenatal period [1-4]. Thus, the elimination of magnesium deficiency is a feasible condition for reducing the frequency of disorders of intrauterine fetal development and morbidity of children at all stages of development [4].

Magnesium is a universal regulator of physiological and biochemical processes of the body. In terms of specific gravity in the chemical composition of the human body, magnesium ranks fourth after sodium, potassium and calcium, and in terms of content in the cell - second after potassium. $60 \%$ of magnesium is contained in bones, forming their structure together with calcium, there is only $0.3 \%$ of magnesium in the blood serum (normally the concentration is $0.70-0.98 \mathrm{mmol} /$ 1). The intracellular fraction of magnesium is $39 \%$, up to $80-90 \%$ of which is in complex with ATP [5].

The most magnesium-dependent tissues are: muscle tissue, placenta, uterus, brain, myocardium, which have the maximum density of mitochondria. One of the reasons for the development of magnesium deficiency is pregnancy and lactation. Pregnancy and lactation conditionally physiological conditions - are a serious test for a woman's health, and at the same time the need for magnesium increases 2-3 times and amounts to 500-700 mg per day. During pregnancy, with insufficient and poor-quality nutrition, in the presence of immunological changes in the body, a variety of diseases can occur [6].

A lack of magnesium during pregnancy in the mother can lead to tetany (cramps of skeletal muscles, more often legs), spasmophilia, metabolic disorders (gestational diabetes, hyperinsulinemia, impaired oxalate metabolism), early aging of the placenta with the formation of petrificates, placental insufficiency, premature birth, hyperaldosteronism and hypertension, preeclampsia and eclampsia, as well as miscarriage [7].

Miscarriage is a spontaneous termination of pregnancy in the period from conception to 37 weeks, which occurs in 18-23\% of cases. In the structure of all obstetric complications, this pathology is $29.7 \%$.

The rapid development of biomedical sciences and translational medicine has expanded our understanding of the molecular foundations of life in various periods of human life. A special place in this case is occupied by the study of the biological "non-reproductive" effects of steroid hormones, in particular progesterone, which for a long time was considered as an essential hormone - an indicator of fertility of the menstrual cycle and a key hormone of pregnancy [8].

Like any steroid hormone, progesterone is synthesized from cholesterol and formed in two consecutive stages. Since progesterone is synthesized from cholesterol, which opens the chain of biosynthesis of steroid sex hormones and corticosteroids and is found everywhere in human cell membranes, including in the central nervous system, the multifaceted effects of progesterone at the systemic, organ, tissue and local levels become clear [9].

Classical and non-classical receptors of progesterone and its metabolites.

The main biological effect of progesterone is carried out with the help of classical receptors (type A and type B), responsible mainly for genomic effects and common in all parts of the brain. The extragenomic effects of progesterone are realized due to its membrane receptors, which are localized mainly in the pre- and postsynaptic sections of neurons and, presumably, their interaction with the ligand provides direct and rapid effects at the synaptic level. In addition, this parasynaptic arrangement of extrahypothalamic progesterone receptors in the $c$ contributes to the formation of a faster response to the hormone stimulus due to the absence of the need to pass the genomic pathway of the corresponding effect. Progesterone binds to these receptors with high selectivity and affinity, which is necessary for the realization of its neuroprotective properties [10].

Sufficient levels of progesterone and magnesium are among the most important factors that determine the normal development of the embryo and affect the progression of pregnancy. Literature data say that with the symptoms of the threat of termination of pregnancy, the function of the placenta is disrupted. There is a persistent increase in uterine tone, which reduces fetoplacental blood flow and leads to a deterioration in the transport of oxygen and nutrients to the fetus. As a result, placental insufficiency develops, the main symptom of which is a violation of the hormonal function of the fetoplacental complex. To date, the rational tactics of managing pregnant women with the threat of termination of pregnancy includes the appointment of micronized progesterone in combination with magnesium preparations [11].

The purpose of the study: to assess the level of magnesium and the functional state of pregnant women 
against the background of taking micronized progesterone and magnesium preparation.

\section{MATERIALS AND METHODS}

On the basis of the Orenburg Clinical Perinatal Center, we conducted a study of 30 pregnant women aged 25 to 35 years, with a gestation period of up to 12 weeks, who live in the Orenburg region. The selection of test subjects was carried out on a voluntary basis. The exclusion criteria were the presence of acute and exacerbation of chronic diseases.

Depending on the intake of micronized progesterone and magnesium preparation, we divided the women into three groups: group I took both micronized progesterone and magnesium preparation, group II - only micronized progesterone, III - did not take (control group). Group I and II took micronized progesterone at a dose of $200 \mathrm{mg}$ 2 times a day for three weeks, group I took magnesium preparation $470 \mathrm{mg} 3$ times a day.

To assess the functional state of pregnant women, we determined the adaptive potential of the cardiovascular system using the Baevsky R.M. index and conducted a SAN test (well-being, activity, mood). In order to assess the level of magnesium, biochemical blood tests were carried out [12].

In order to calculate the index of adaptive potential of the cardiovascular system (the index of R.M. Bayevsky), we used the formula:

$$
\begin{aligned}
\varangle \mathrm{AP}=(0,0011 & \times \mathrm{PE})+(0,014 \times S B P)+(0,008 \\
& \times D B P)+(0,009 \times \mathrm{BW})-(0,009 \\
& \times H)+(0,014 \times \mathrm{A})-0,27 \nabla \wedge
\end{aligned}
$$

where AP is the adaptive potential of the circulatory system in points; $\mathrm{PR}$ is the pulse rate in beats per minute; $\mathrm{SBP}$ is systolic blood pressure in $\mathrm{mmHg}$; $\mathrm{DBP}$ is diastolic blood pressure in $\mathrm{mmHg} ; \mathrm{H}$ is height in $\mathrm{cm}$; $\mathrm{BW}$ is body weight in $\mathrm{kg}$; $\mathrm{A}$ is age in years. According to the values of AP, the functional state of the patient was determined: AP below 2.60 - satisfactory adaptation of the circulatory system, AP from 2.60 to 3.09 - tension of the adaptation mechanisms, AP from 3.10 to 3.49 - unsatisfactory adaptation, $\mathrm{AP}=3.50$ and above - failure of adaptation.

Determination of the level of magnesium in the blood on an empty stomach was carried out in an accredited laboratory using a biochemical analyzer Sapphire-400 (normal magnesium levels are 0.70-0.98 mmol/l).

The "WBAM" test is used to assess functional states such as well-being, activity and mood of respondents. The questionnaire consists of 30 pairs of opposite characteristics, between which there is a scale of indices

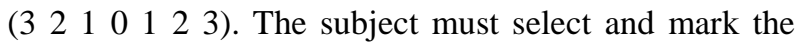
figure that most accurately reflects his condition at the time of the examination. The amount obtained on each scale is in the range from 10 to 70 and allows you to identify the functional state of the patient at a given time according to the principle: ( $<30$ points - low score; $30-50$ points - average score; $>50$ points - high score).

Statistical analysis was performed using nonparametric methods. The data are presented in the form of median (M), lower and upper quartiles (25-27 percentiles). The critical significance level was taken as $\mathrm{p}<0.05$.

\section{RESULTS AND DISCUSSION}

When assessing the physiological parameters (height, weight, blood pressure, pulse), the individual results of all examined women corresponded to the recommended values.

Satisfactory adaptation of the circulatory system was observed in women of groups I and III (I - 1.34 (1.22-1.47); III - $1.44(1.36-1.52))$. In group II, the median of the Baevsky RM index is on the border of satisfactory and strenuous adaptation (2.6 (1.29-2.73)). When evaluating individual indicators, it was revealed that $60 \%$ of women in this group have tension in the mechanisms of adaptation of the circulatory system. We determined statistically significant differences between indicators of adaptive potential between women of

\begin{tabular}{|c|c|c|c|}
\hline \multirow[t]{2}{*}{ Indicator } & \multicolumn{3}{|l|}{ Groups } \\
\hline & I $(n=10)$ & $\|(n=10)$ & III $(n=10)$ \\
\hline $\begin{array}{l}\text { The index of } \\
\text { R.M. Bayevsky }\end{array}$ & $\begin{array}{l}1.34 \\
(1.22-1.47)\end{array}$ & $\begin{array}{l}1.44 \\
(1.36-1.52) *\end{array}$ & $\begin{array}{l}2.6 \\
(1.29-2.73)\end{array}$ \\
\hline
\end{tabular}
group II and III ( $\mathrm{p}<0.05)$ (Table 1).

Table 1. The index of R.M. Bayevsky

In pregnant women of group I and III, the blood magnesium levels are within the normal range (I -0.79 (0.74-0.85); III - $0.75(0.65-0.82))$. In group II, where women took only micronized progesterone, the median level of magnesium in the blood is 0.65 (0.61-0.69), which indicates a magnesium deficiency. After analyzing the data, we determined statistically significant differences between the magnesium content in the blood

\begin{tabular}{|c|c|c|c|}
\hline \multirow[t]{2}{*}{ Indicator } & \multicolumn{3}{|l|}{ Groups } \\
\hline & I $(n=10)$ & II $(n=10)$ & III $(n=10)$ \\
\hline $\begin{array}{l}\text { The level of } \\
\text { magnesium in } \\
\text { the blood }\end{array}$ & $\begin{array}{l}0.79 \\
(0.74-0.85)\end{array}$ & $\begin{array}{l}0.65 \\
(0.61-0.69) \text { * }\end{array}$ & $\begin{array}{l}0.75 \\
(0.65-0.82)\end{array}$ \\
\hline
\end{tabular}
between groups II and III ( $\mathrm{p}<0.05$ ) (Table 2 ).

Table 2. The level of magnesium in the blood

After analyzing the data obtained using the "WBAM" questionnaire, statistically significant 
differences were revealed between groups II and III in terms of activity and mood (Table 3 ).

Table 3. Results of the "WBAM" test of pregnant women taking micronized progesterone and magnesium preparation

\begin{tabular}{|l|l|l|l|}
\hline \multirow{2}{*}{ Indicator } & \multicolumn{2}{l|}{ Groups } \\
\cline { 2 - 4 } & I $(n=10)$ & II $(n=10)$ & III $(n=10)$ \\
\hline Well- & 49.5 & 49.5 & 56.5 \\
being & $(44.8-58.2)$ & $(31.5-55.0)$ & $(46.3-63.8)$ \\
\hline Activity & 44.0 & 28.0 & 50.0 \\
& $(39.0-50.3)$ & $(25.2-29.8)^{\star}$ & $(36.8-64.25)$ \\
\hline Mood & 61.5 & 33.5 & 59.0 \\
& $(58.5-66.8)$ & $(30.8-47.8)^{\star}$ & $(54.2-64.8)$ \\
\hline
\end{tabular}

In particular, in group II women, activity and mood indicators are significantly lower than in group III pregnant women.

\section{CONCLUSION}

The problem of miscarriage and premature birth is one of the most urgent medical and social problems. Premature birth is the birth of a sick mother with the birth of a sick child. In obstetric practice, miscarriage and premature birth lead to serious perinatal risks and complications. In developed countries, the frequency of premature birth ranges from 5 to $9 \%$, in various regions of the Russian Federation - from 6 to $15 \%$, according to $\mathrm{WHO}$, the frequency of this pathology ranges from 5 to $30 \%$. Every year, more than 15 million premature babies are born in the world. In the structure of early neonatal mortality, 60-70 \% are premature infants, 50 $\%$ of them have neurological disorders of varying severity.

The birth of a premature baby, especially with extremely low and very low body weight, is a complex medical and social problem, because it is directly associated with material and economic costs. The quality of life of a premature baby correlates with the gestation period, the volume and timeliness of obstetric care and resuscitation measures for the newborn.

Currently, obstetricians face two main tasks: detection of threatening premature birth and preparation of the fetus for premature birth with the help of adequate but safe medications. Numerous scientific studies in recent years have been aimed at improving the methods of diagnosis, prevention and treatment of premature birth.

Adequate micronutrient provision of a woman's body allows avoiding many pregnancy complications that negatively affect the health of the mother and fetus, including microvascular pathology.
Timely diagnosis of magnesium deficiency in the vast majority of cases makes it possible to prescribe a simple, safe and effective treatment that reduces the risk of complications in mother and child tenfold.

When evaluating objective indicators using the Bayevsky R.M. index, it was revealed that the majority of women taking only micronized progesterone had a strain on the adaptive potential of the cardiovascular system. This result is an alarming symptom when using micronized progesterone, since young women who do not have chronic diseases participated in the study. In women taking both progesterone and magne B6 forte, a satisfactory adaptation of the circulatory system is observed. The "WBAM" test showed a significantly significant effect of micronized progesterone on activity and mood, since these indicators were reduced, and with the simultaneous use of progesterone and magnesium preparation, the indicators were within normal limits.

Such results confirm the effectiveness of the combined use of micronized progesterone and magnesium preparation, because simultaneous use reduces certain side effects (drowsiness, fatigue, dizziness) of micronized progesterone. In addition, magnesium preparations contribute to a better adaptation of the cardiovascular system.

\section{REFERENCES}

[1] V.E. Radzinsky, I.B. Manukhin, On common misconceptions concerning the use of gestagens in the clinical practice of an obstetrician-gynecologist, Status Praesens, Gynecol., obstetr., infert. Marriage 3(32) (2016) 1-5.

[2] G.M. Savelyeva, G.E. Sukhin, V.N. Serov, V.E. Radzinsky, Obstetrics: National leadership, GEOTAR-Media, Moscow, 2015, 1200 p.

[3] A.N. Strizhakov, Pathophysiology of the fetus and placenta, GEOTAR-Media, Moscow, 2015, 176 p.

[4] M. Kashanian, T. KaramiAbd, N. Sheikhansari et al., Efficacy of daily rectal micronized progesterone for prevention of preterm delivery: a randomized clinical trial, J. Matern. Fetal. Neonatal. Med. 14 (2020) 1-7.

[5] O.I. Lisitsyna, E.G. Khilkevich, The use of magnesium preparations during pregnancy, Med. Council 7 (2018).

[6] G.B. Dikke, The role of magnesium in physiological pregnancy: contraversions and evidence, Med. Council 19 (2016).

[7] M. Makrides, D.D. Crosby, E. Bain, C.A. Crowther, Magnesium supplementation in pregnancy, Cochrane Database of Systematic Reviews, John Wiley and Sons Ltd, 2014. 
Retrieved from: https://doi.org/10.1002/14651858.CD000937.pub2

[8] L. Spatling, H.G. Classen, K. Kisters et al., Supplementation of Magnesium in Pregnancy, J. of Pregn. and Child Health 04(01) (2017). Retrieved from: https://doi.org/10.4172/2376-127x.1000302

[9] E.G. Khilkevich, O.I. Lisicyna, Magnesium supplementation during pregnancy, Med. Council 7 (2018) 50-53. Retrieved from: https://doi.org/10.21518/2079-701x-2018-7-50-53

[10] M. Bullarbo, N. Ödman, A. Nestler et al., Magnesium supplementation to prevent high blood pressure in pregnancy: A randomised placebo control trial, Arch. of Gynecol. and Obstetr. 288(6) (2013) 1269-1274. Retrieved from: https://doi.org/10.1007/s00404-013-2900-2

[11] D.I. Pietro, A. Visalli, G. Panagia et al., Risk factors for voluntary interruption of pregnancy and possible preventive public health actions, J. of Prevent. Med. and Hyg. 59(4) (2018) E311-E314. Retrieved from: https://doi.org/10.15167/24214248/jpmh2018.59.4.941

[12] L.M. Dalton, D.M. Ní Fhloinn, G. Gaydadzhieva et al., Magnesium in pregnancy, Nutrit. Rev. 74(9) (2016) 549-557. Retrieved from: https://doi.org/10.1093/nutrit/nuw018 